ARTICLE

\title{
Hierarchical porous silicon structures with extraordinary mechanical strength as high- performance lithium-ion battery anodes
}

Haiping Jia ${ }^{1}$, Xiaolin Li ${ }^{1 凶}$, Junhua Song ${ }^{1}$, Xin Zhang $\mathbb{1}^{2}{ }^{2}$, Langli Luo ${ }^{3}{ }^{3}$, Yang $\mathrm{He}^{3}$, Binsong $\mathrm{Li}^{4}$, Yun Cai ${ }^{5}$, Shenyang $\mathrm{Hu}^{5}$, Xingcheng Xiao ${ }^{4}$, Chongmin Wang $\mathbb{1}^{3}{ }^{3}$, Kevin M. Rosso ${ }^{2}$, Ran $\mathrm{Yi}^{1}$, Rajankumar Patel ${ }^{1} \&$ Ji-Guang Zhang (D) ${ }^{1 凶}$

Porous structured silicon has been regarded as a promising candidate to overcome pulverization of silicon-based anodes. However, poor mechanical strength of these porous particles has limited their volumetric energy density towards practical applications. Here we design and synthesize hierarchical carbon-nanotube@silicon@carbon microspheres with both high porosity and extraordinary mechanical strength (>200 MPa) and a low apparent particle expansion of $40 \%$ upon full lithiation. The composite electrodes of carbon-nanotube@silicon@carbon-graphite with a practical loading $\left(3 \mathrm{mAh} \mathrm{cm}^{-2}\right)$ deliver $750 \mathrm{mAh} \mathrm{g}^{-1}$ specific capacity, $<20 \%$ initial swelling at $100 \%$ state-of-charge, and $\sim 92 \%$ capacity retention over 500 cycles. Calendered electrodes achieve $~ 980 \mathrm{mAh} \mathrm{cm}^{-3}$ volumetric capacity density and $<50 \%$ end-of-life swell after 120 cycles. Full cells with $\mathrm{LiNi}_{1 / 3} \mathrm{Mn}_{1 / 3} \mathrm{Co}_{1 / 3} \mathrm{O}_{2}$ cathodes demonstrate $>92 \%$ capacity retention over 500 cycles. This work is a leap in silicon anode development and provides insights into the design of electrode materials for other batteries.

\footnotetext{
${ }^{1}$ Energy and Environment Directorate, Pacific Northwest National Laboratory, Richland, Washington 99352, USA. ${ }^{2}$ Physical and Computational Sciences Directorate, Pacific Northwest National Laboratory, Richland, Washington 99352, USA. ${ }^{3}$ Environmental Molecular Sciences Laboratory, Pacific Northwest National Laboratory, 3335 Innovation Boulevard, Richland, Washington 99354, USA. ${ }^{4}$ General Motors Research and Development Center, 30500 Mound Road, Warren, Michigan 48090, USA. ${ }^{5}$ National Security Directorate, Pacific Northwest National Laboratory, Richland, Washington 99352, USA.

凶email: xiaolin.li@pnnl.gov; jiguang.zhang@pnnl.gov
} 
A s batteries become increasingly indispensable to the daily life of human society with their expanded use from cell phones and portable electronics to electric vehicles and electric grids, the demands on batteries with even higher energy densities are continuously increasing ${ }^{1-4}$. The use of nanostructured materials has advanced battery technologies, particularly the development of high-performance and low-cost lithiumion batteries (LIBs) and beyond ${ }^{5-11}$. The development of silicon (Si) anodes for next-generation LIBs has benefited tremendously from the introduction of nanotechnology. In the past decade, landmark progress has been achieved in promoting the electrochemical performance of Si anodes using Si-based nanostructures including $\mathrm{Si}$ nanoparticles, nanowires, nanotubes, yolk-shell structures, etc ${ }^{12-26}$. Our group also has developed mesoporous Si sponge and designed porous Si/graphite $(\mathrm{Gr})$ composite anodes to mitigate pulverization and reduce particle swelling, hence achieving high-performance anodes at practical loadings ${ }^{27,28}$. An et al. ${ }^{29}$ recently reported an ant-nest-like bulk porous $\mathrm{Si}$, which demonstrates impressive performance in both half-cell and fullcell configurations.

Although nanostructured $\mathrm{Si}$ can mitigate its structure failure originated from large volume change during lithiation/delithiation processes, the properties intrinsic to nanomaterials such as high surface area and low tap density are also detrimental for their electrochemical performances and the manufacturing for practical batteries. For example, the nanostructured Si materials with a large surface area often have a poor adhesion to the current collector at high loading $\left(>3 \mathrm{mAh} \mathrm{cm}^{-2}\right)$ and more serious parasitic electrolyte decomposition reactions lead to lower first cycle Coulombic efficiency $(\mathrm{CE})^{23,25}$. Efforts on binder, electrolyte, surface coating, and prelithiation are needed to improve the electrode integrity, solid electrolyte interphase (SEI) residency and lithium loss in full cells using $\mathrm{Si}$ anodes ${ }^{30-37}$.

Furthermore, many porous nanostructure $\mathrm{Si}$ particles have poor mechanical strength and are easy to be broken during calendering, which is a critical/must step in practical battery manufacturing to reduce the parasitic reactions, electrolyte consumption, and improve battery energy density and safety. Recently, it has been realized that the excellent mechanical strength is as essential as superb electrochemical performance for nanostructured battery materials ${ }^{38-40}$. Yolk-shell Si@titanium dioxide with improved mechanical strength and Si-nanolayerembedded Gr can be calendered to reach high-capacity density ${ }^{17,41}$. However, it is still an onerous quest to design nanostructures with satisfactory mechanical and electrochemical performance for battery applications.

Carbon nanotubes (CNTs), which are known for high electronic conductivity and excellent mechanical properties ${ }^{42-44}$, have been harnessed into composites with nano-Si to improve the cycle life of $\mathrm{Si}$ anodes ${ }^{45-47}$. In this work, unique hierarchical porousCNT@Si@carbon (CNT@Si@C) microspheres of high mechanical strength and limited particle swelling upon full lithiation are developed with well-engineered structural parameters (small primary Si particle size, controlled porosity, and surface area, high-quality carbon coating, etc). CNT@Si microspheres are prepared by in-situ thermite reduction of microspheres of CNT@silica $\left(\mathrm{CNT} @ \mathrm{SiO}_{2}\right)$ core-shell coaxial cables. The well-designed CNT@Si microspheres can absorb the volume change of $\mathrm{Si}$ and hence demonstrate apparent particle expansion of $\sim 30 \%$ upon full lithiation, which is $1 / 10$ of the expansion of bulk Si particles. The yarn-ball-like CNT@Si microspheres after carbon coating, denoted as CNT@Si@C, has 40\% particle expansion upon full lithiation. It also can withstand $>200 \mathrm{MPa}$ pressure without breakdown and therefore can tolerate the industrial calendering process for electrode manufacturing. With this unique structure, the CNT@Si@C anode delivers a reversible capacity of $\sim 1500 \mathrm{mAh}^{-1}$ and $87 \%$ capacity retention over 1500 cycles at $1 \mathrm{~mA} \mathrm{~cm}{ }^{-2}$. The practical CNT@Si@C-Gr composite anodes at $3 \mathrm{mAh} \mathrm{cm}^{-2}$ areal loading exhibit $\sim 750 \mathrm{mAh} \mathrm{g}^{-1}$ specific capacity, $<20 \%$ initial swelling at $100 \%$ state-of-charge, and $\sim 92 \%$ capacity retention over 500 cycles. The calendered electrodes demonstrate $\sim 980 \mathrm{mAh} \mathrm{cc}^{-3}$ volumetric capacity density and $<50 \%$ end-of-life (EOL) swell after 120 cycles. The full cell with $\mathrm{LiNi}_{1 / 3} \mathrm{Mn}_{1 / 3} \mathrm{Co}_{1 / 3} \mathrm{O}_{2}$ cathode demonstrates $>92 \%$ capacity retention over 500 cycles. Our work represents an effective strategy in the development of Si anodes for LIBs and possibly other battery chemistry with fundamental understanding of the electro-mechanical stability of porous Si.

\section{Results}

Structural design of hierarchical CNT@Si@C microspheres. Figure 1 shows the schematic synthesis process (Fig. 1a) and structure characterization of the key intermediate products of $\mathrm{CNT@SiO} 2$ (Fig. 1b-e) and the final carbon-coated hierarchical porous CNT@Si@C microspheres (Fig. 1f-i). The $\mathrm{CNT} @ S i O_{2}$ microspheres (Fig. 1b) were prepared by emulsion of the CNT@SiO 2 core-shell coaxial cables (Fig. 1c), which was prepared with a sol-gel method ${ }^{48}$. The $\mathrm{SiO}_{2}$ layer of $\sim 10-20 \mathrm{~nm}$ thick was uniformly coated on the surface functionalized high-quality CNTs (Supplementary Fig. 1, outer diameter 20-40 nm) and formed core-shell coaxial cables of $\sim 60-80 \mathrm{~nm}$ (Fig. 1c and Supplementary Fig. 2). Scanning transmission electron microscopy (STEM) and energy-dispersive X-ray spectroscopy (EDS) line scan (Fig. 1d-e) corroborated the coating uniformity with slightly varying thickness. The $\mathrm{SiO}_{2}$ coating was designed by controlling the tetraethoxysilane (TEOS) percentage so that the final CNT@Si@C anodes have a target-specific capacity of $\sim 1000 \mathrm{mAh} \mathrm{g}^{-1}$ based on the total electrode weight (see Supplementary Fig. 3 and design detail in Supplementary Materials).

Because of the unique structure design, the $\mathrm{CNT} @ \mathrm{SiO}_{2}$ microspheres have uniformly distributed $\mathrm{Si}$, oxygen, and carbon (Supplementary Fig. 4 ) even though the particle is $\sim 6-8 \mu \mathrm{m}$ large in diameter (Supplementary Fig. 5). Furthermore, the CNT@Si microspheres produced from the $\mathrm{CNT} @ S i O_{2}$ microspheres by aluminothermic reduction maintain the spherical morphology and similar size (Supplementary Fig. 6). The Si and carbon also are uniformly distributed in the CNT@Si microspheres (Supplementary Fig. 6). The formation of Si was corroborated by the Xray diffraction (XRD) (Supplementary Fig. 7) and further characterization of the final product of CNT@Si@C (Fig. 1f-i). No signal associated to $\mathrm{Al}$ is detected by $\mathrm{X}$-ray photoelectron spectroscopy (XPS) for CNT@Si, reflecting the complete removal of $\mathrm{Al}$ during the washing steps (Supplementary Fig. 8).

CNT@Si was coated with a layer of carbon using chemical vapor deposition (CVD) method to help prevent the oxidization of nano-Si in air and control the surface area, and hence the electrochemical performance (vide infra). CVD carbon, even though is not as robust as pitch carbon ${ }^{49}$, has the advantage in easy pore filling and forming thin and uniform carbon coating on as much surface of the porous Si as possible.CNT@Si@C has reduced surface area and porosity (Supplementary Figs. 9-11 and Supplementary Table 1) and thus results in reduced parasitic reaction from electrolyte decomposition and improved electrochemical performance. The tap density of the CNT@Si@C is $0.5 \mathrm{~g} \mathrm{cc}^{-1}$, more than three times larger than the tap density of nano-Si powder $\left(\sim 0.15 \mathrm{~g} \mathrm{cc}^{-1}\right)^{19}$. XPS analyses (Supplementary Fig. 12) showed $\sim 6-8 \mathrm{wt} \%$ of oxygen in CNT@Si and CNT@Si@C, similar to the EDS measurement results (Supplementary Fig. 13, 7.3-8.5 wt\%). Supplementary Fig. 14 is Raman spectra showing high-quality carbon with similar G/D ratio to that of the CNT was infiltrated into the pores of hierarchical 
a

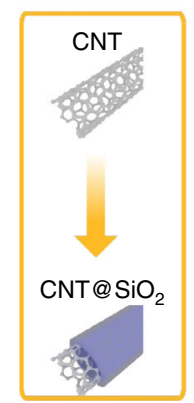

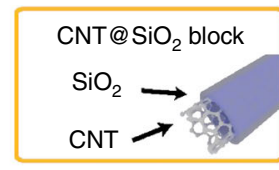

Emulsion

Water evaporation \& condensation

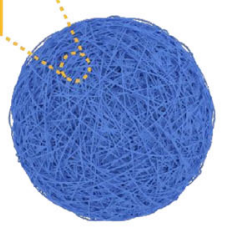

$\mathrm{CNT} @ \mathrm{SiO}_{2}$ microsphere

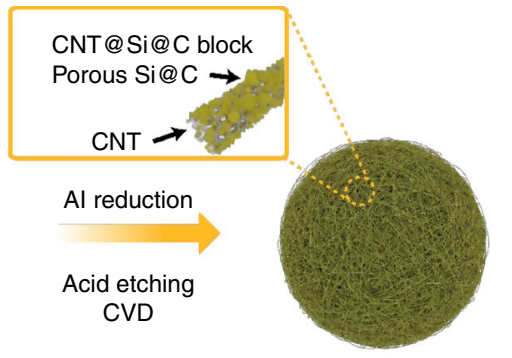

CNT@Si@C microsphere
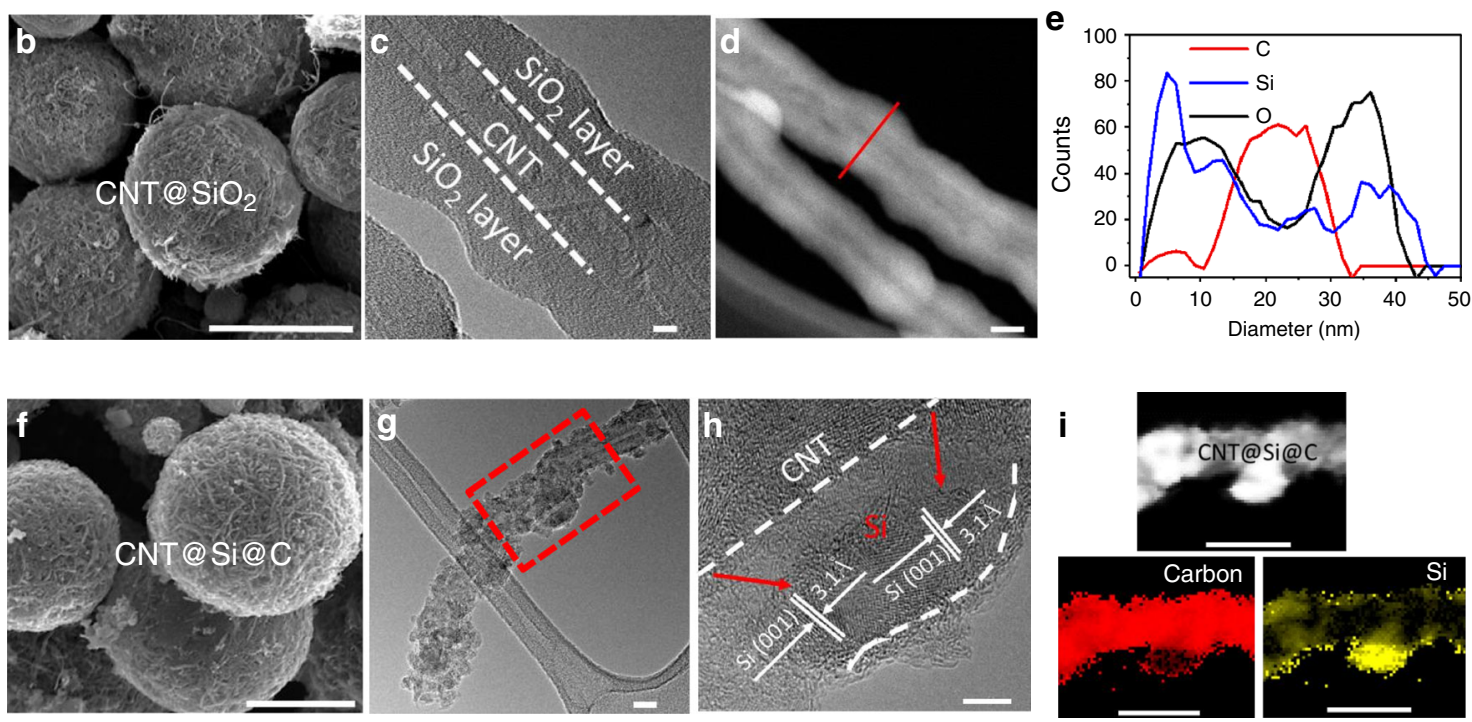

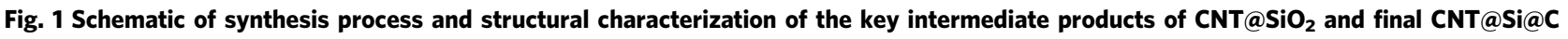

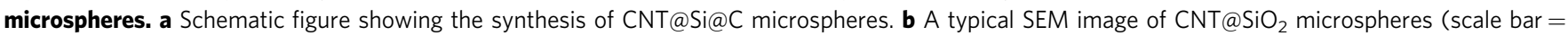
$5 \mu \mathrm{m})$.c A representative TEM image of a CNT@SiO ${ }_{2}$ core-shell coaxial cable (scale bar $\left.=5 \mu \mathrm{m}\right)$.d A STEM image of the CNT@SiO $\mathrm{CN}_{2}$ cables $(\mathrm{scale}$ bar $=$ $20 \mu \mathrm{m}$ ). e EDS line scan of the CNT@SiO 2 cable marked in d. Small discrepancy of Si and O due to beam effect from prolonged scanning. $\mathbf{f}$ A typical SEM image of CNT@Si@C microspheres (scale bar=3 $\mu \mathrm{m}$ ).g Low-magnification TEM image of a composite cable from a CNT@Si@C microsphere (scale bar $=20 \mu \mathrm{m})$, h HRTEM image of the cable in $\mathbf{g}$ (scale bar $=5 \mu \mathrm{m})$. $\mathbf{i}$ EDS mapping of the marked area in $\mathbf{g}$ (scale bar $=50 \mu \mathrm{m}$ ).

porous CNT@Si and coated on the surface. TEM and EDS mapping show the detailed composite structure of CNT@Si@C (Fig. 1g-i). Figure 1 and Supplementary Fig. 15 show that Si particles with various sizes up to tens of nanometers were decorated on the CNT. XRD analysis shows that Si has an average crystallite size of $\sim 30-40 \mathrm{~nm}$, which is consistent with the distribution histogram from TEM (Supplementary Fig. 16). Highresolution (HR) TEM (Fig. 1h) reveals the crystalline structure of some large nanoparticles with lattice fringes of $3.1 \AA$, corresponding to $\mathrm{Si}$ (111) plane, while the mapping shows some amorphous $\mathrm{Si}$ or fine clusters. The carbon layer of $\sim 4 \mathrm{~nm}$ thick uniformly coats on Si nanoparticles (Fig. 1h-i and Supplementary Fig. 15). Fourier-transform infrared spectroscopy study (Supplementary Fig. 17) show the chemical binding between Si, CNT, or CVD carbon coating. The improved mechanical or electrical integrity is due to the chemical bonding between CNT, Si, and C, as well as the physical attachment and CVD carbon-coating effect.

A porous structure is essential to accommodate the volume expansion of $\mathrm{Si}$, yet it needs to be well-tailored to retain sufficient volumetric capacity density and high mechanical strength that can withstand calendering and other battery assembly procedures.

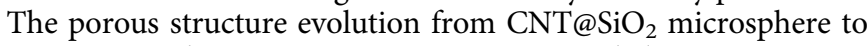
CNT@Si and CNT@Si@C were monitored by cross-section scanning electron microscopy (SEM) and gas absorption (Fig. 2 and Supplementary Figs. 9-11). The SEM study showed improved pore distribution and porous structure for CNT@Si compared with $\mathrm{CNT}_{\mathrm{SiO}}$. The gas absorption showed the surface area, pore volume, and average pore diameter increase from CNT@SiO $\mathrm{S}_{2}$ to $\mathrm{CNT@Si,} \mathrm{whereas} \mathrm{these} \mathrm{parameters} \mathrm{decrease}$ for CNT@Si@C (Supplementary Table 1). The final carboncoated CNT@Si microspheres,CNT@Si@C, have a surface area $\left(\sim 60 \mathrm{~m}^{2} \mathrm{~g}^{-1}\right)$ smaller than many nano-Si materials, while still having an average pore diameter of $20 \mathrm{~nm}$ to accommodate the expansion of Si nanoparticles anchored on CNTs.

The effects of the porous structure of CNT@Si and CNT@Si@C in accommodating the Si volume expansion were investigated by in-situ particle swelling measurements and electrochemical tests. With the unique highly porous yarn-balllike structure, both CNT@Si and CNT@Si@C microspheres deliver the expected effect on suppressing the swelling of porous Si particles upon lithiation, while maintaining overall structural integrity. In-situ TEM characterization of a representative CNT@Si microsphere with $\sim 1.12 \mu \mathrm{m}$ in diameter expanded to a sphere of $\sim 1.14 \mu \mathrm{m}$ at partial lithiation and to $\sim 1.21 \mu \mathrm{m}$ at full lithiation (Supplementary Fig. 18a-c and Supplementary Movie 1). The three-dimensional (3D) expansion calculated from the sphere volume is $\sim 27 \%$ and no cracking was observed. The hierarchical porous structure is effective in mitigating the swelling and maintaining structural integrity. Multiple particles were similarly checked and the average structure swelling is $\sim 30 \%$, which is $1 / 10$ the expansion of bulk Si particles (Supplementary Fig. 18d-f and Supplementary Movie 2). In case of CNT@Si@C, 

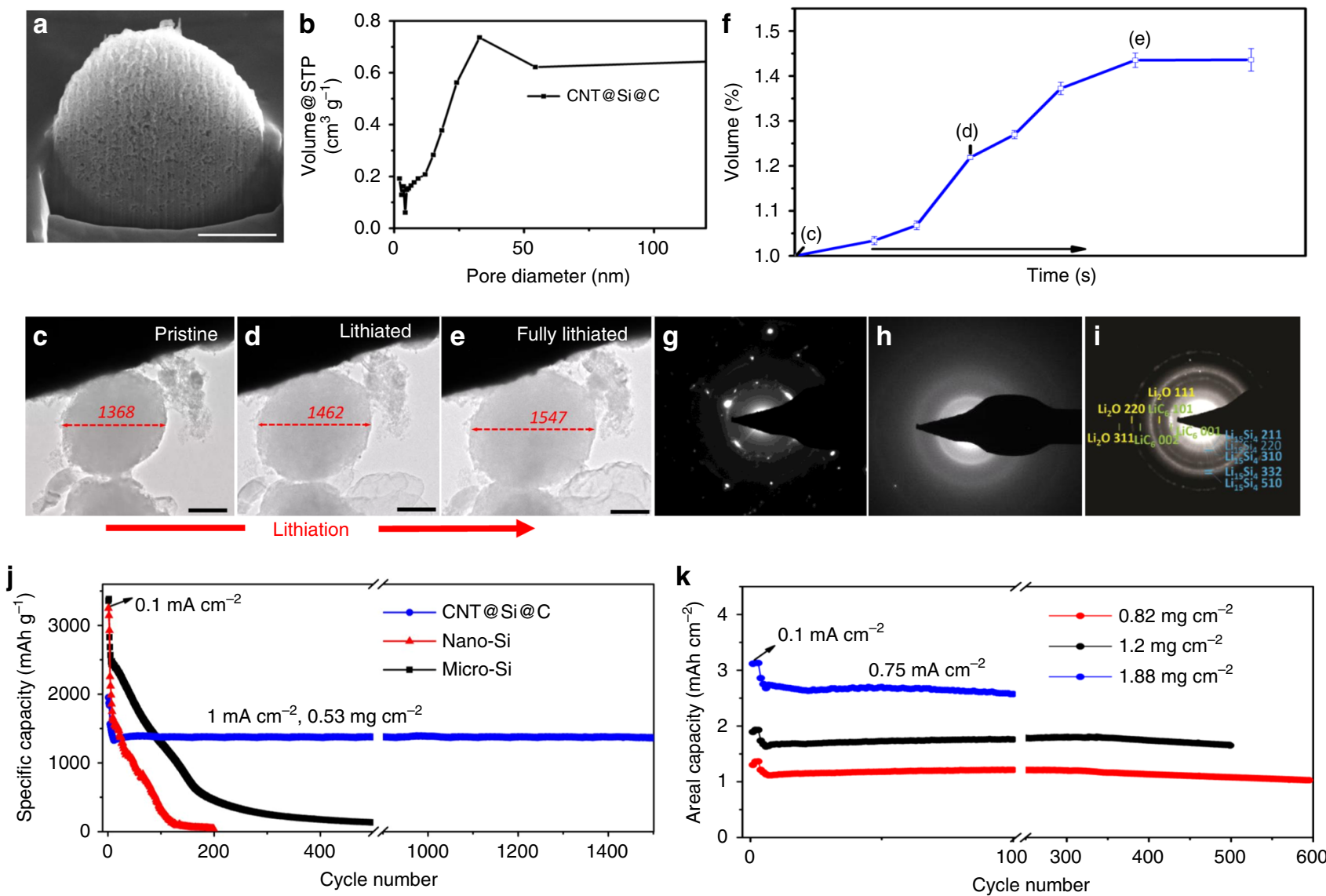

Fig. 2 Characterization of the CNT@Si@C porous structure, particle swelling, and electrochemical performance. a Cross-section SEM of a typical CNT@Si@C microsphere (scale bar=1 $\mu$ m).b Pore diameter distribution of CNT@Si@C from gas absorption. c-e In-situ TEM images of a CNT@Si@C particle at different lithiation states (scale bar $=0.5 \mu \mathrm{m}$ ). The unit of the numbers in figures is $\mathrm{nm}$. $\mathbf{f}$ Volume expansion curve of the particle recorded during the lithiation process. $\mathbf{g}-\mathbf{h}$ The selected area electron diffraction (SAED) patterns of CNT@Si@C at different lithiation states. $\mathbf{j}$ Long-term cycling of CNT@Si@C, nano-Si, and micro-Si. k Long-term cycling of CNT@Si@C at different mass loadings.

the in-situ particle swelling measurement showed that a typical CNT@Si@C sphere at full lithiation has a volume expansion of $\sim 44 \%$ (Fig. 2c-f and Supplementary Movie 3). Selected area electron diffraction patterns during the lithiation have shown that the porous $\mathrm{Si}$ changed from polycrystalline (Fig. 2g) to amorphous (Fig. $2 \mathrm{~h}$ ) and then to crystalline $\mathrm{Li}_{15} \mathrm{Si}_{4}$ phase after full lithiation (Fig. 2i). The increased volume expansion of CNT@Si@C is due to the decrease of pore size and pore volume after carbon coating (Supplementary Table 1). In-situ TEM (Supplementary Fig. 19) also showed that the size of Si particles increases as the lithiation process goes on, while no fracture was observed even after full lithiation. The particles demonstrate good flexibility throughout the lithiation process and the bonding between CNT and Si remains good during the repeated cycling (see Supplementary Movie 4).

The electrochemical performance of CNT@Si@C in a side-byside comparison with nano-Si or micron-Si as shown in Fig. $2 \mathrm{j}$ and Fig. $2 \mathrm{k}$, respectively, at various electrode loadings provides the final and best proof of having achieved the desired porous structure. Figure $2 \mathrm{j}$ showed much better cycling stability of the CNT@Si@C than nano-Si or micron-Si at similar low electrode loading(0.75 mAh cm $\left.{ }^{-2}\right)$.CNT@Si@C showed almost no fading after the formation cycles. The capacity retention is $>87 \%$ (compared with the first cycle after formation) over $\sim 1500$ cycles. Control experiments using conventional nanostructured CNT-Sicarbon composites and CNT@Si microsphere anodes were conducted as well. The nanostructured CNT-Si-carbon composites present a fast capacity fade because of poor adhesion between the electrodes and current collectors, whereas the CNT@Si microspheres demonstrate an initial capacity of 2441 $\mathrm{mAh} \mathrm{g}^{-1}$ with $72 \%$ capacity retention after 240 cycles (Supplementary Fig. 20). The above side-to-side comparison further confirms the advantage of the yarn-ball-like CNT@Si@C microsphere design and the importance of the carbon coating. Figure $2 \mathrm{k}$ demonstrates that the CNT@Si@C electrode can still deliver excellent cyclability at increased electrode loadings. The electrode with a practical loading of $\sim 3 \mathrm{mAh} \mathrm{cm}^{-2}$ still retains $\sim 90 \%$ capacity after 100 cycles.

Detailed analysis of the battery performance further corroborated the success of our initial structure design. First, the first delithiation capacity of the CNT@Si@C electrode is 1900 $\mathrm{mAhg}^{-1}$ at low current density of $0.1 \mathrm{~mA} \mathrm{~cm}^{-2}$ and $\sim 1500 \mathrm{mAh} \mathrm{g}^{-1}$ at $1 \mathrm{~mA} \mathrm{~cm}^{-2}$ (Fig. $2 \mathrm{j}$ and Supplementary Fig. 21). With $\sim 14 \mathrm{wt} \% \mathrm{CNT}$ and $20 \mathrm{wt} \%$ of CVD carbon (Thermogravimetric analysis in Supplementary Fig. 22), the $\mathrm{Si}$ in the composite has $2850 \mathrm{mAh} \mathrm{g}^{-1}$ specific capacity; this is almost the delithiation capacity of commercial nano-Si, corroborating the structural design (Supplementary Fig. 3). Second, postmodern analysis of the electrodes showed that the CNT@Si@C microspheres preserved the original morphology even after 500 deep cycles (Supplementary Fig. 23). Third, the average thickness of pristine CNT@Si@C is $42.5 \mu \mathrm{m}$, which increases to $53 \mu \mathrm{m}$ after initial lithiation (Supplementary Figs. 24-26). Thus, the CNT@Si@C electrode swelling at 100\% state-of-charge (SOC) is $24.7 \%$ [(53-42.5)/42.5]. In comparison with the particle swelling from in-situ TEM, the smaller electrode swelling at the electrode level is ascribed to the additional porosity 

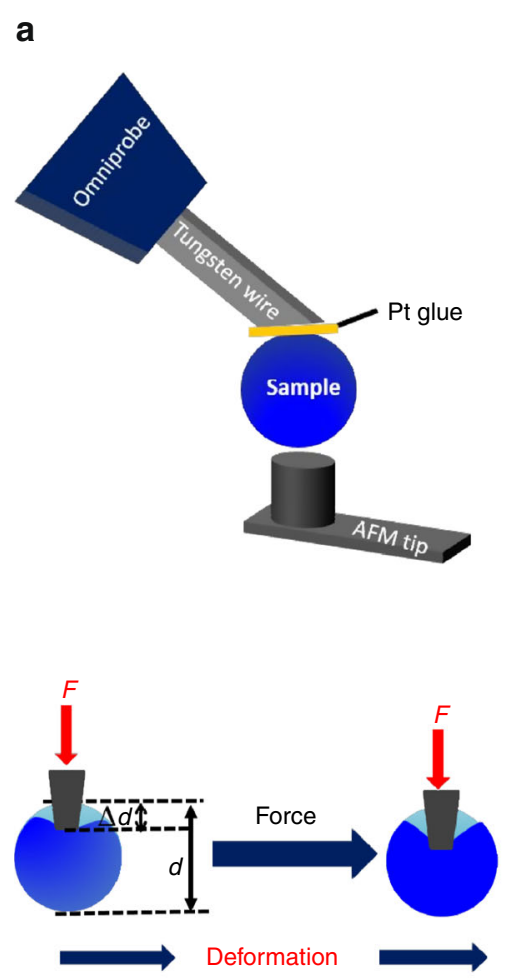
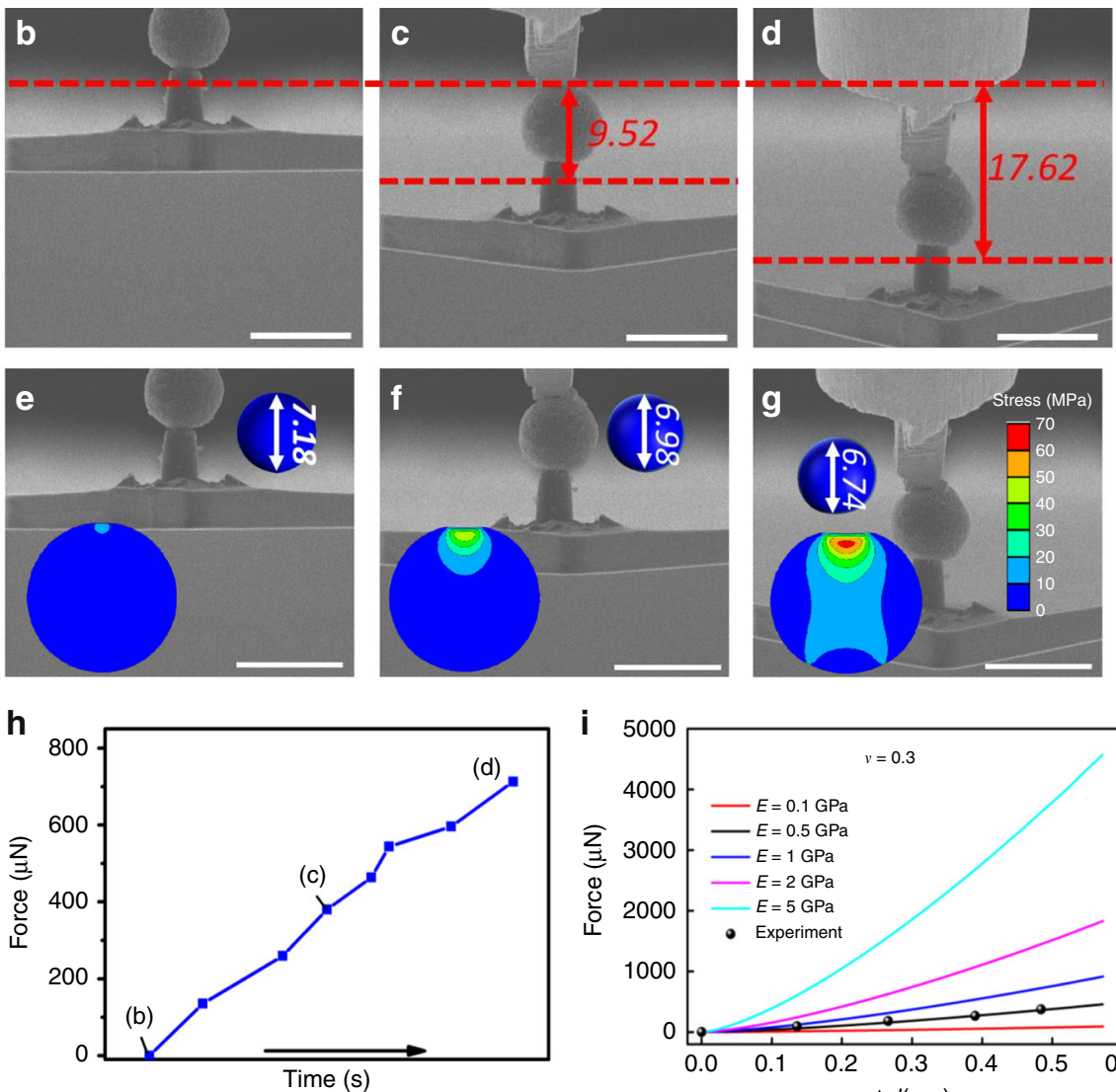

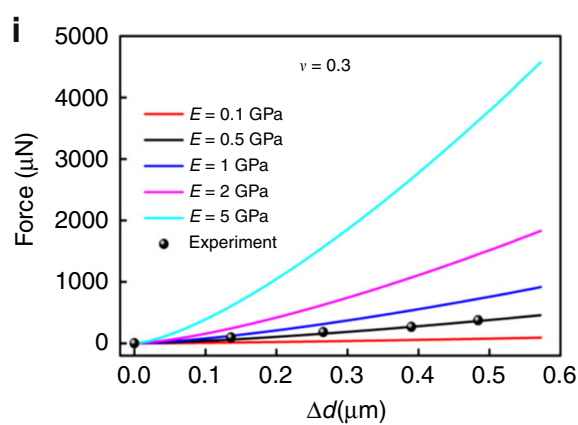

Fig. 3 Mechanical strength of CNT@Si@C microspheres. a Schematic of the in-situ AFM-SEM experiment for the mechanical strength measurement. b-d AFM tip displacement/cantilever deflection of a typical CNT@Si@C sphere under an applied force: b beginning of the pressing; c the middle point of the pressing; $\mathbf{d}$ right before the breakdown of the particle. e-g The different deformation states of a CNT@Si@C sphere: e $\Delta d=0.05 \mu \mathrm{m} ; \mathbf{f} \Delta d=0.27 \mu \mathrm{m}$; $\mathbf{g} \Delta d=0.49 \mu \mathrm{m}$, and the corresponding distribution of the von Mises stress ( $\mathrm{MPa}$ ) from FE simulation (inset) with the Young's modulus $0.5 \mathrm{GPa}$ and the Poisson ratio 0.3. Scale bar for Fig. $3 \mathrm{~b}-\mathrm{g}$ is $10 \mu \mathrm{m}$. The unit for the numbers in the figures is $\mu \mathrm{m}$. $\mathbf{h}$ The curve of force vs time during $\mathbf{b}$ to $\mathbf{d}$. $\mathbf{i}$ Experimental data (dots) and FE simulation curve of the force vs particle deformation $\Delta d$ with the Poisson ratio 0.3 and different Young's modulus.

in the electrode. The SEI formation, which is known to lead to the increase of electrode thickness, was not severe for the CNT@Si@C microsphere anodes. Last, the CNT@Si@C-NMC333 full cells demonstrate good cycling stability with $>91.7 \%$ capacity retention over 100 cycles (Supplementary Fig. 27).

Mechanical strength of the CNT@Si@C microspheres. The mechanical strength of CNT@Si@C was measured by in-situ atomic force microscopy (AFM) and SEM experiments. Figure 3a shows the experimental schematic of pressing an individual particle against an AFM tip with appropriate spring constant. A single microsphere was welded to the rigid $\mathrm{W}$ probe, which is connected to an OMNI probe. The microsphere and the $\mathrm{W}$ probe have no relative movement and moves slowly as a whole to press a fixed AFM tip. The force on the AFM tip and the deformation of the microspheres were recorded in-situ to assess the Young's modulus, Poisson ratio, and mechanical strength of the CNT@Si@C. Supplementary Fig. 28 shows the typical fabrication process of the AFM tip for this mechanical strength measurement. Knowing the diameter and area of the AFM tip is as important as knowing the spring constant for accurate calculation of the resistive force. Figure $3 \mathrm{~b}-\mathrm{d}$ were recorded at the beginning, in the middle, and before breakage of a microsphere with a diameter of $\sim 7.23 \mu \mathrm{m}$ (see the pressing process in Supplementary Movie 5 and Supplementary Fig. 28). The AFM tip displacement/ cantilever deflection and the deformation of the microsphere $(\Delta d)$ were carefully measured (see the results in Supplementary Figs. 29 and 30). The compressive force applied on the particle, which is calculated from the AFM tip displacement/cantilever deflection and spring constant, is plotted in Fig. $3 \mathrm{~h}$. The results in Fig. $3 \mathrm{~h}$ and Supplementary Fig. 29 show that the particle can withstand a total force of $705 \mu \mathrm{N}$ or an equivalent pressure of $\sim 181 \mathrm{MPa}$ before breakage. Similar mechanical measurements were systematically investigated on particles of different sizes and using different AFM tips to produce reliable results and minimize the sample/measurement variation (Supplementary Fig. 31 and Supplementary Movie 6). From these results, we can see clearly that the CNT@Si@C has remarkable mechanical strength that can withstand $\sim 200 \mathrm{MPa}$ pressure without cracking or serious deformation. Considering the calculations were from the moments right before the fracture of the microsphere happened, the force has not reached the fracture point yet it already corresponds to $\sim 200 \mathrm{MPa}$ pressure, demonstrating high mechanical strength of our hierarchical porous microspheres.

To assess the Young's modulus, a finite element (FE) method was used to simulate the deformation of the microsphere with exactly the same boundary conditions as that in the in-situ AFM-SEM experiments, i.e., fixed displacement constraint on the welded area, given deformation $(\Delta d)$ boundary condition on the contacted area between the microsphere and AFM tip, and stressfree boundary condition on the rest surface of the microsphere. The von Mises stress distributions for the sequence of different deformation states are shown in Fig. 3e-g. The von Mises stress 
beneath the pressing tip is much larger than that near the bottom due to the different boundary conditions at the bottom and top of the particle. The high von Mises stress should cause breaks near the pressing tip, as visualized in Supplementary Movie S6. The curves of the force vs. time and the deformation of the particle $(\Delta d)$ calculated from FEM simulations for different elastic properties are plotted in Fig. $3 \mathrm{~h}-\mathrm{i}$. Comparing the simulation and experimental results, the Young's modulus and Poisson ratio are determined to be $0.5 \mathrm{GPa}$ and 0.3 , respectively. The model settings and simulation results are presented in detail in the Supplementary Materials (Supplementary Figs. 32 and 33, and Supplementary Movie 7).

A flat punch experiment (the substrate and the probe are two infinite planes in comparison with the microsphere) using freestanding microsphere also was carried out for further evaluation of the mechanical strength of the CNT@Si@C material (Supplementary Figs. 34 and 35). The young's modulus measured from the flat punch experiment is $\sim 0.5-0.8 \mathrm{GPa}$, which matches well with the result from in-situ AFM-SEM measurements and FE simulations. It supports that the results from our mechanical measurements and FE simulations are reliable. The stress at the end of the elastic deformation in the flat punch experiment is $\sim 48.4 \mathrm{MPa}$, whereas it is $\sim 91.2 \mathrm{MPa}$ at the end of densification. The microsphere mechanical strength from the flat punch experiments is between the two numbers but smaller than the value measured by in-situ AFM-SEM design because of different experiment settings and boundary conditions (the displacement constraint in the in-situ AFM-SEM experiments should reduce the deformation and result in increased fracture strength). It must be noted that the elastic deformation strength of $48.4 \mathrm{MPa}$ is still larger than the facture strength of core-shell structures ${ }^{17}$ and maybe other porous structures. It is believed that the high mechanical strength of the CNT@Si@C is from the superior properties of $\mathrm{CNT}$ and the microsphere yarn-ball-like matrix structure. CNT is known to have high Young's modulus values between 12 and $50 \mathrm{GPa}$, and is hard to be compressed axially or radially ${ }^{42,50}$. In addition, the CNT yarn ball may yield slightly and lose some porosity under very high compressing force, but it will not break. The appropriate Si-to-CNT-to-C ratio also is helpful to the strength of the structure, but further analyses are needed for the correlation of structure design and mechanical properties.

The remarkable mechanical strength enables CNT@Si@C to undergo the calendering process, which is particularly important for $\mathrm{Gr}$ composite electrodes and practical application (The uncalendered electrodes have high porosity and it will lead to the increase of electrolyte amount and hence lower the cell energy density, even though the specific capacity/cycling stability of anode may be good. This has been largely neglected in most of previous battery research.). Supplementary Fig. 36 shows the top and cross-section views of electrodes with different calendering
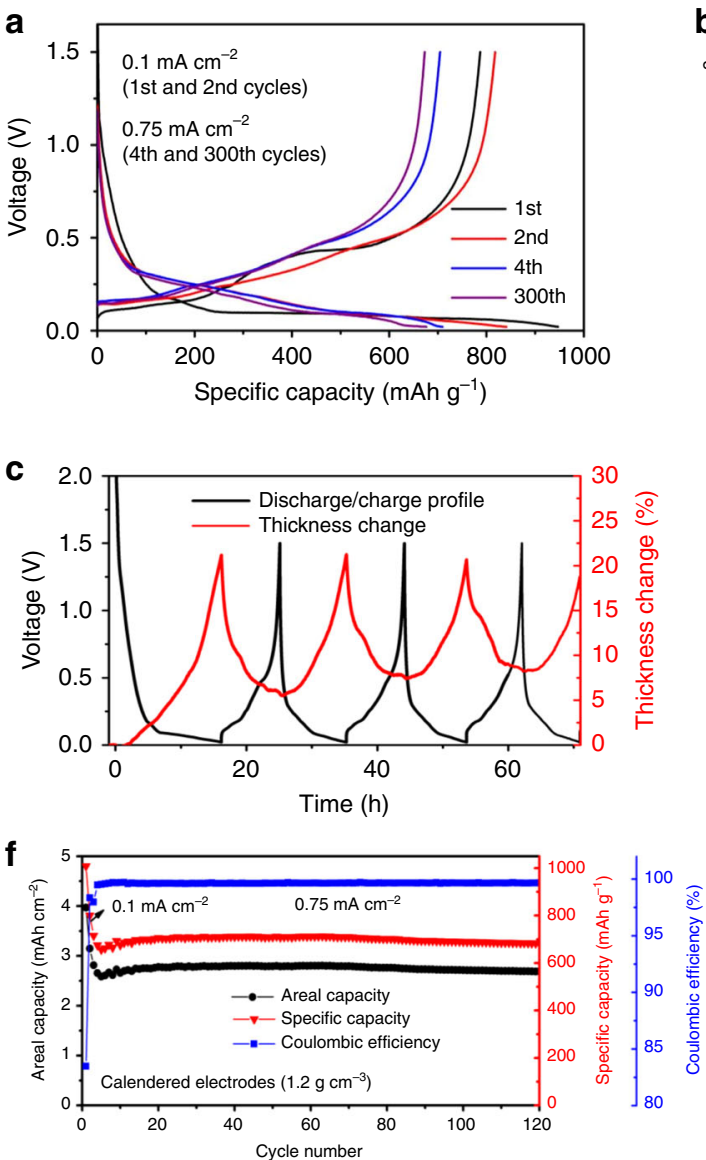
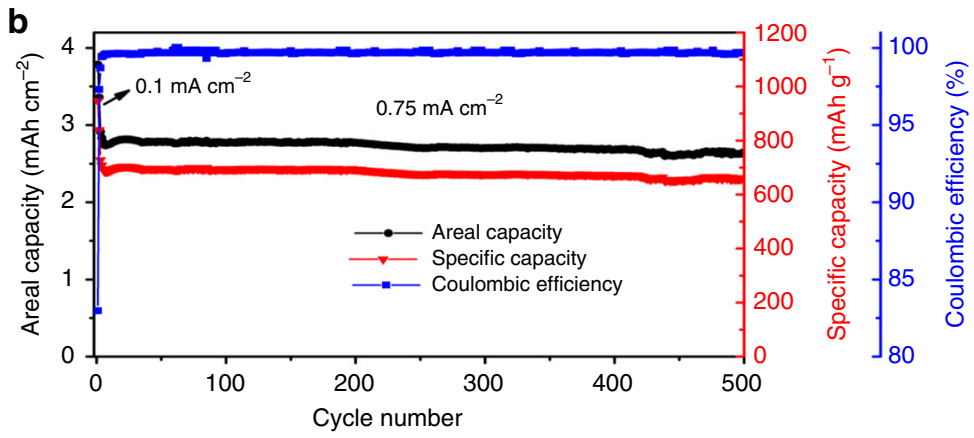

d
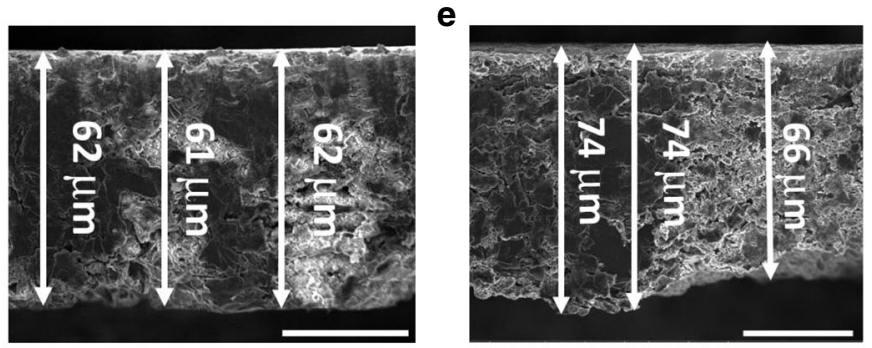

g

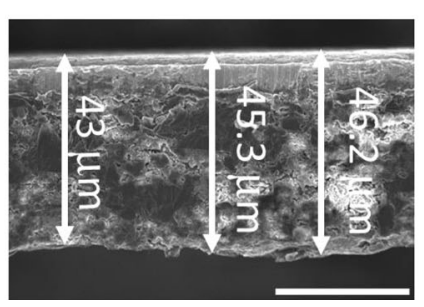

h

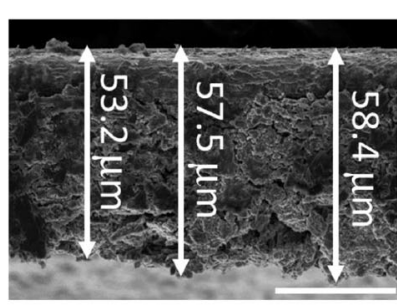

Fig. 4 Electrochemical characterization of the CNT@Si@C-graphite anodes (30 wt\% : 58 wt\%) in half-cells. a Typical voltage curves of a CNT@Si@C and graphite composite anode with $3 \mathrm{mAh} \mathrm{cm}^{-2}$ loading. The mass loading of the electrodes in Fig. 4 is $4.0 \mathrm{mg} \mathrm{cm}^{-2}$. b Cycling behavior of the same anode in $\mathbf{~ a . ~} \mathbf{c}$ In-situ measurement of electrode swelling during discharge-charge at $0.2 \mathrm{~mA} \mathrm{~cm}^{-2}$. $\mathbf{d ~ S E M}$ image of a pristine electrode (scale bar $=30 \mu \mathrm{m}$ ). e SEM image of a fully lithiated electrode after 1 cycle (scale bar $=30 \mu \mathrm{m}$ ). $\mathbf{f}$ Cycling stability of an electrode calendered to $1.2 \mathrm{~g} \mathrm{~cm}-3 . \mathbf{g}$ SEM image of an electrode after calendering to $1.2 \mathrm{~g} \mathrm{~cm}^{-3}$ while before cycling (scale bar $=30 \mu \mathrm{m}$ ). $\mathbf{h}$ SEM image of the calendered electrode at full lithiation state after 120 cycles (scale bar $=30 \mu \mathrm{m}$ ). 

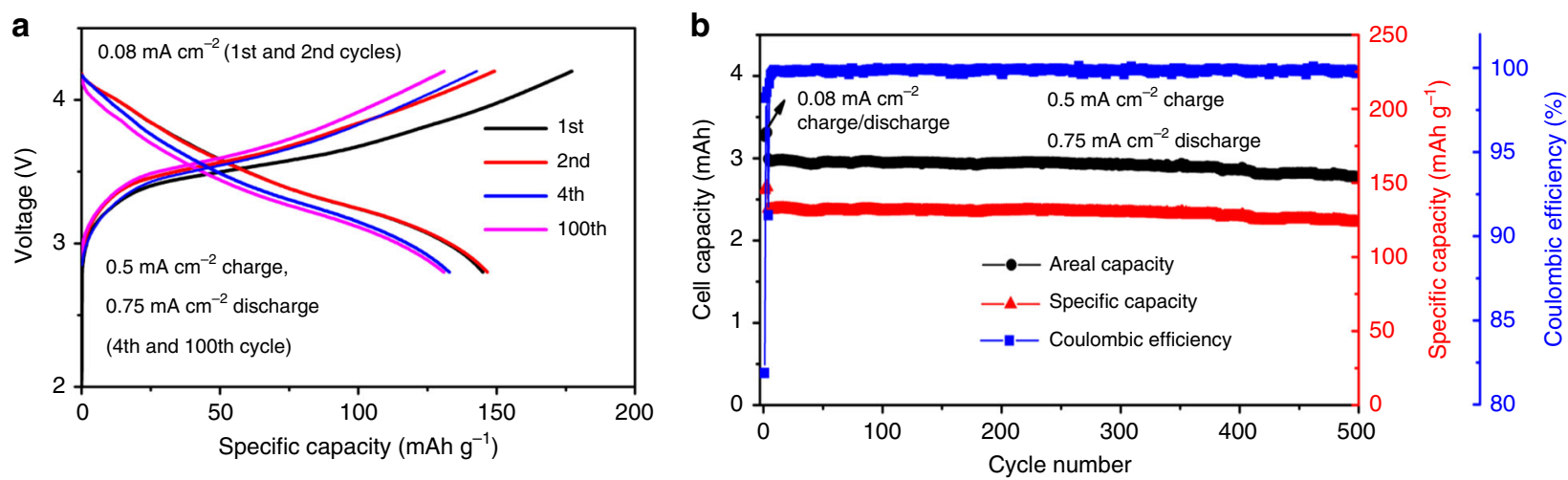

Fig. 5 Electrochemical performance of a typical full cell with $\mathrm{Li}\left(\mathrm{Ni}_{1 / 3} \mathrm{Mn}_{1 / 3} \mathrm{Co}_{1 / 3}\right) \mathrm{O}_{2}$ cathode and pre-cycled CNT@Si@C and graphite composite anode. a Voltage profiles. $\mathbf{b}$ Long-term cycling data of the full cell in $\mathbf{a}$.

treatment. In spite of the flattened surface, the CNT@Si@C in the electrodes calendered to $\sim 1.2 \mathrm{~g} \mathrm{~cm}^{-3}$ (20 $\mu \mathrm{m}$ thick) still preserves a spherical morphology, similar to that in as-casted electrodes.

Electrochemical characterization of CNT@Si@C and graphite composite anodes. With the unique nanostructure of outstanding mechanical and electrochemical performance, the CNT@Si@C microspheres were mixed with Gr to prepare practical composite electrodes. Figure 4 shows the electrochemical performance of high loadingCNT@Si@C-Gr composite electrode (30wt\% : 58 wt $\%)$ obtained in half-cells. The charge-discharge curves (Fig. 4a) showed typical profiles for the Si-Gr anodes between 0.02 and $1.5 \mathrm{~V}$, similar to that previously reported in the literature $27,41,51$. The first cycle CE of the CNT@Si@C-Gr composite electrode is $\sim 84 \%$, higher than that of CNT@Si@C (75\%; see Fig. 2 and Supplementary Fig. 21). The specific capacity is $\sim 844 \mathrm{mAh} \mathrm{g}^{-1}$ (second formation cycle) at low current density of $0.1 \mathrm{~mA} \mathrm{~cm}^{-2}$ and $\sim 718 \mathrm{mAh} \mathrm{g}^{-1}$ at $0.75 \mathrm{~mA} \mathrm{~cm}^{-2}$, indicating good rate performance even at a practical loading of $\sim 3 \mathrm{mAh} \mathrm{cm}^{-2}$.

From the fact that the CNT@Si@C has good cycling stability (Fig. 2) and minimized particle swelling of $\sim 40 \%$ (Fig. 2), the composite anodes of CNT@Si@C-Gr can be expected to have excellent cycling performance and minimized electrode swelling. Figure 4b shows excellent cycling life of CNT@Si@C-Gr with $>92 \%$ capacity retention over 500 cycles. The CE at stable cycling is $\sim 99.9 \%$.

In-situ electrochemical dilatometer measurement and ex-situ SEM studies of the pristine electrode and the electrode at $100 \%$ SOC showed a consistent result of small electrode swelling (Fig. 4c-e). Figure $4 \mathrm{c}$ shows the swelling (red) of a typical high loading electrode upon cycling (black). The largest electrode expansion is $\sim 21 \%$ at full lithiation and $\sim 6 \%$ at delithiation states. Figure $4 \mathrm{~d}-\mathrm{e}$ are cross-section SEM images of a pristine electrode and an electrode after the first lithiation to $100 \%$ SOC. The electrode thickness before testing is $\sim 50.7 \mu \mathrm{m}$ in average [61.7 $\mu \mathrm{m}$ (the total thickness in average) $-11 \mu \mathrm{m}$ (the thickness of $\mathrm{Cu}$ foil)], whereas the average electrode thickness at the first full lithiation is $\sim 59.7 \mu \mathrm{m}(70.7 \mu \mathrm{m}-11 \mu \mathrm{m})$. The electrode expansion at full lithiation is $\sim 18.3 \%$ [(59.7 - 50.7)/50.7], consistent with the in-situ dilatometer result.

The extraordinary mechanical strength of the nanostructure CNT@Si@C enables the electrodes to be calendered to high densities. Supplementary Fig. 37 shows the calendered electrodes with the spherical morphology of CNT@Si@C maintained even when the electrodes were pressed to a density up to $1.4 \mathrm{~g} \mathrm{~cm}^{-3}$. The electrodes showed similar cycling stability with and without calendering. The electrode calendered to $\sim 1.2 \mathrm{~g} \mathrm{~cm}^{-3}$ shows $96 \%$ capacity retention over 120 cycles (Fig. $4 \mathrm{f}$ ), whereas the electrode calendered to $\sim 1.4 \mathrm{~g} \mathrm{~cm}^{-3}$ has $\sim 91 \%$ capacity retention (Supplementary Fig. 38 ). The specific capacities also are similar to the non-calendered electrodes even though the electrode loading is $\sim 3 \mathrm{mAh} \mathrm{cm}^{-2}$. The polarization introduced by calendering is negligible in this case. The volumetric capacity densities of the electrodes of 1.2 and $1.4 \mathrm{~g} \mathrm{~cm}^{-3}$ are $~ 844$ and $980 \mathrm{mAh} \mathrm{cm}^{-3}$ (Supplementary Table 2), calculated according to the second discharge capacities, 799 and $796 \mathrm{mAh} \mathrm{g}^{-1}$, respectively (Fig. 4f and Supplementary Fig. 38). This is $\sim 1.4$ to 1.7 times of $\mathrm{Gr}$ electrodes ${ }^{52}$.

The SOC and EOL swelling of the calendered electrodes can be estimated from SEM analyses of the electrode thickness change before and after cycling. For the electrode calendered to $1.2 \mathrm{~g} \mathrm{~cm}^{-3}$ density, the swelling at $100 \%$ SOC after the first cycle is $\sim 23.5 \%$ [(42.6 - 34.5)/34.5] (Supplementary Fig. 39). In the case of EOL swelling, the thickness increased from $33.8 \mu \mathrm{m}$ (44.8 (the average thickness of the entire electrode) -11 (the $\mathrm{Cu}$ foil thickness), Fig. $4 \mathrm{~g}$ and Supplementary Table 2) to $\sim 45.4 \mu \mathrm{m}(56.4-11$, Fig. $4 \mathrm{~h}$ and Supplementary Table 2) after 120 cycles. The EOL swelling is $\sim 34 \%$ [ $(45.4-33.8) / 33.8]$. The electrode calendered to $1.4 \mathrm{~g} \mathrm{~cm}^{-3}$ shows thickness increase from $\sim 28.1 \mu \mathrm{m}$ (Supplementary Fig. 26 and Supplementary Table 2) to $\sim 40.7 \mu \mathrm{m}$ (Supplementary Fig. 38) after 120 cycles. The EOL swelling is $\sim 45 \%$.

CNT@Si@C and Gr composite anodes also show excellent performance in full cells against $\mathrm{Li}\left(\mathrm{Ni}_{1 / 3} \mathrm{Mn}_{1 / 3} \mathrm{Co}_{1 / 3}\right) \mathrm{O}_{2}$ (NMC) cathodes. NMC cathodes were prepared with appropriate loading (see experiment part for details) and tested at different current densities in a half-cell configuration. With an areal loading of $\sim 2.4 \mathrm{mAh} \mathrm{cm}^{-2}$, the NMC cathode delivers a specific capacity of $\sim 150 \mathrm{~mA} \mathrm{~h} \mathrm{~g}^{-1}$ between 2.7 to $4.3 \mathrm{~V}$ (Supplementary Fig. 40). The typical full cell with the pristine CNT@Si@C-Gr anode has $\sim 77 \%$ first cycle CE and $76 \%$ capacity retention over 120 cycles (Supplementary Fig. 41). In order to further improve the cycling performance of full cells, the anodes were first cycled in a half-cell configuration against $\mathrm{Li}$ metal before the full-cell test (see Methods part for details). Good full-cell performance was obtained with an $n / p$ ratio of $\sim 1.1: 1$ (anode/cathode mass ratio $=0.22$ ). Figure 5 presents a typical full-cell performance with NMC333 cathode and pre-cycled CNT@Si@C-Gr anode of $\sim 3 \mathrm{~mA}$ h. Figure 5a shows the charge/discharge voltage curves of a typical full cell cycled between 2.8 and $4.2 \mathrm{~V}$. The specific discharge capacity of NMC cathode is $\sim 145 \mathrm{~mA} \mathrm{~h} \mathrm{~g}^{-1}$, similar to those from the half-cell measurement. It also demonstrates excellent cycle life with capacity of $92 \%$ in 500 cycles (Fig. 5b).

\section{Discussion}

On the basis of its excellent electrochemical performance, mechanical strength, and structural integrity demonstrated above, CNT@Si-based hierarchical porous nanostructure holds great 
promise for practical next-generation battery applications. It not only can fulfill the performance requirements of practical Sibased anodes in cycling stability, CE, high volumetric capacity density, minimized electrode initial, and EOL swelling, but is also suitable for standard industrial processing procedures including calendering. The designed CNT@Si@C is among the top performance Si anodes (Supplementary Table 3) and provides insight for design $\mathrm{Si}$ anodes towards practical applications. Further development of CNT@Si-based hierarchical porous nanostructure using other scalable and economical methods, such as spray-drying or mechanical condensation will enable next generation of high-energy Li-ion batteries. The rational design of nanostructured battery materials and electrodes in this work also opens a new dimension in material design for other batteries.

\section{Methods}

Material synthesis. The hierarchical porous CNT@Si microspheres were prepared by aluminothermic reduction of the $\mathrm{CNT}_{\mathrm{NSiO}}$ microspheres from sol-gel and emulsion synthesis (see details in Supplementary Materials). Briefly, CNT (cheap Tubes, outer diameter: $\sim 30-50 \mathrm{~nm}$, insider diameter: $\sim 5-10 \mathrm{~nm}$ ) was coated with polyvinylpyrrolidone (PVP, Sigma-Aldrich, M.W. 40,000) by $2 \mathrm{~h}$ sonication in a $0.5 \mathrm{wt} \%$ PVP water solution. The surface modified CNT after filtration was dispersed in an ethanol and $\mathrm{H}_{2} \mathrm{O}$ solution (10:1 volume ratio). Appropriate amount of $\mathrm{NH}_{3} \cdot \mathrm{H}_{2} \mathrm{O}(25 \mathrm{wt} \%)$ and tetraethoxysilane (TEOS) were added into the above dispersion slowly. The product was filtered after $24 \mathrm{~h}$ and washed with ethanol and deionized water, and re-dispersed in water. The $\mathrm{CNT} @ \mathrm{SiO}_{2}$ water dispersion was mixed with 1-octadecene solution $(0.3 \mathrm{wt} \%)$ in a $1: 8$ volume ratio and homogenized to form emulsion. An aqueous suspension of the silica-coated carbon tubes $\left(\mathrm{CNT} @ \mathrm{SiO}_{2}\right)$ forms numerous micrometer-sized water droplets dispersed in the oil phase. The mixture was heated at $95 \sim 98^{\circ} \mathrm{C}$ for $4 \mathrm{~h}$. During the heating process and water evaporation, colloidal particles aggregate and the $\mathrm{CNT}_{0} \mathrm{SiO}_{2}$ cables in the

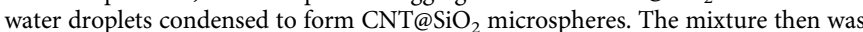
centrifuged to collect $\mathrm{CNT} @ \mathrm{SiO}_{2}$ microspheres, which later were washed with petroleum ether. The final powder was annealed at $550^{\circ} \mathrm{C}$ for $1 \mathrm{~h}$ in argon for removal of the organic molecules and condensation of the $\mathrm{CNT}_{\mathrm{SiO}}$ microspheres. Then, a mixture of $\mathrm{CNT} @ \mathrm{SiO}_{2}, \mathrm{AlCl}_{3}$ and $\mathrm{Al}$ metal (weight ratio of $\sim 1: 6$ : 1.6) was sealed in a Swagelok ${ }^{\circledast}$ reactor and heated for $15 \mathrm{~h}$ at $350^{\circ} \mathrm{C}$ under $\mathrm{Ar}$ atmosphere. After cooling, the products were first immersed in $\mathrm{H}_{2} \mathrm{O}$ and subsequently in $1 \mathrm{M} \mathrm{HCl}$ to remove byproducts. The product of CNT@Si was collected after filtration, washing with $\mathrm{H}_{2} \mathrm{O}$ and ethanol, and vacuum-drying. CVD carbon coating of CNT@Si was conducted at $700{ }^{\circ} \mathrm{C}$ for $30 \mathrm{~min}$ using acetylene as the carbon source 28

Characterization. Surface morphology and cross-section of the microspheres and electrodes were studied using a focused ion-beam scanning electron microscope (FEI Helios Nanolab) with EDS features. For the measurement of initial and EOL swell, the cells were disassembled with anodes at 100\% lithiated state. Before SEM measurement, the electrodes were washed with anhydrous dimethyl carbonate for three times and dried completely in a glovebox's antechamber under vacuum.

TEM, HRTEM, and EDS elemental line scan and mapping were carried out on FEI Titan 80-300 STEM equipped with a condenser lens Cs corrector. In-situ swelling of CNT@Si and CNT@Si@C microspheres upon lithiation was investigated by a solid-state "nano-battery" configuration ${ }^{28}$. The porous structure of the samples were determined by nitrogen adsorption measurement using a Micromeritics ASAP 2020.

Mechanical property measurement and simulation. Mechanical strength of the CNT@Si@C microspheres was investigated by in-situ AFM-SEM test. An AFM probe with a spring constant of $40 \mathrm{~N} \mathrm{~m}^{-1}$ was attached to the sample holder with the conducting tape. The AFM tip was fabricated to cylindrical shape from triangular pyramid that was pre-oriented, cut, and polished by focused ion-beam milling. The diameter of the tip are designed within an appropriate range of $\sim 1.5-3 \mu \mathrm{m}$. A random picked Si@CNT@C microsphere was attached to the tungsten probe with Pt glue. The sphere was bought into contact with the prepared AFM tip by the 3D-piezo-manipulator and pressure was applied to the particle by exerting a displacement against the AFM tip. The force acting on the particle was calculated by measurement of the displacement of AFM tip during the pressing. The FE software Abaqus CAE 6.14-4 (SIMULIA, 2015) was used to simulate the particle deformation. The symmetries of the modeled specimens were considered to lower the computation time. In the simulations, four-node axisymmetric element (CAX4R) with total 6000 elements was used. The sample was deformed by a same displacement in the experiment.

Battery tests and electrode swelling study. The anodes were prepared by mixing CNT@Si@C material, Super P, and dreambond ${ }^{\circledast}$ polyimide (PI) binder in a weight ratio of $80: 5: 15$. The CNT@Si@C-Gr composite electrodes were composed of
30 wt\% CNT@Si@C, 58 wt\% Gr, 2 wt \% Super p, and 10 wt\% polyacrylic acid (PAA) binder. PAA binder is used for the CNT@Si@C and Gr composite electrode, because PI binder does not work well for the electrode with large amount of Gr, which has large particle size of tens of micrometers. The cathodes were prepared by mixing $96 \mathrm{wt} \% \mathrm{NMC}, 2 \mathrm{wt} \%$ Super P, and $2 \mathrm{wt} \%$ polyvinylidene difluoride binder (2.5 wt\% in $\mathrm{N}$-methyl-2-pyrrolidone). The solution (1 M) of $\mathrm{LiPF}_{6}$ in ethylene carbonate/diethyl carbonate $(3: 7, \mathrm{w} / \mathrm{w})$ and $10 \mathrm{wt} \%$ fluoroethylene carbonate was used as the electrolyte for all the battery tests. The electrochemical performance was evaluated using galvanostatic charge-discharge protocols. For half-cells, Sibased electrodes were cycled between $0.02 \mathrm{~V}$ and $1.5 \mathrm{~V}$ (vs. $\mathrm{Li}^{2} \mathrm{Li}^{+}$), whereas the NMC cathodes were tested from $2.7 \mathrm{~V}$ to $4.3 \mathrm{~V}$. The specific capacity was calculated based on the total weight of the active composite material such as CNT@Si@C, CNT@Si@C-Gr, or NMC, etc. Electrode thickness change during lithiation/delithiation was monitored by an electrochemical dilatometer (EL-Cell, Germany). For the full cells, the CNT@Si@C-Gr electrodes were first pre-cycled in half-cell configuration for three cycles at $0.08 \mathrm{~mA} \mathrm{~cm}^{-2}$. The voltage window was $0.02-1.5 \mathrm{~V}$ and all the cells were collected when they were de-lithiated to $1.5 \mathrm{~V}$. After three formation cycles in half-cells, a stable SEI was expected to form on anodes. The full cells were tested between 2.8 and $4.2 \mathrm{~V}$. The full-cell-specific capacity was calculated based on cathode.

\section{Data availability}

The data that support the findings of this study are available from the corresponding authors upon reasonable request.

Received: 13 March 2019; Accepted: 14 February 2020; Published online: 19 March 2020

\section{References}

1. Armand, M. \& Tarascon, J. M. Building better batteries. Nature 451, 652-657 (2008)

2. Kang, B. \& Ceder, G. Battery materials for ultrafast charging and discharging Nature 458, 190-193 (2009).

3. Scrosati, B., Hassoun, J. \& Sun, Y. K. Lithium-ion batteries. A look into the future. Energy Environ. Sci. 4, 3287-3295 (2011)

4. Schmuch, R., Wagner, R., Horpel, G., Placke, T. \& Winter, M. Performance and cost of materials for lithium-based rechargeable automotive batteries. Nat. Energy 3, 267-278 (2018).

5. Sun, Y. M., Liu, N. A. \& Cui, Y. Promises and challenges of nanomaterials for lithium-based rechargeable batteries. Nat. Energy 1, 16071 (2016).

6. Lu, J. et al. The role of nanotechnology in the development of battery materials for electric vehicles. Nat. Nanotechnol. 11, 1031-1038 (2016).

7. Sun, Y. K. et al. Nanostructured high-energy cathode materials for advanced lithium batteries. Nat. Mater. 11, 942-947 (2012).

8. Ji, X. L., Lee, K. T. \& Nazar, L. F. A highly ordered nanostructured carbonsulphur cathode for lithium-sulphur batteries. Nat. Mater. 8, 500-506 (2009).

9. Sun, J. et al. A phosphorene-graphene hybrid material as a high-capacity anode for sodium-ion batteries. Nat. Nanotechnol. 10, 980-985 (2015).

10. Parker, J. F. et al. Rechargeable nickel-3D zinc batteries: an energy-dense, safer alternative to lithium-ion. Science 356, 414-417 (2017).

11. Wu, H. \& Cui, Y. Designing nanostructured Si anodes for high energy lithium ion batteries. Nano Today 7, 414-429 (2012).

12. Chan, C. K. et al. High-performance lithium battery anodes using silicon nanowires. Nat. Nanotechnol. 3, 31-35 (2008).

13. Lee, J. H. et al. High-energy-density lithium-ion battery using a carbonnanotube-Si composite anode and a compositionally graded $\mathrm{Li}$ $\left[\mathrm{Ni}_{0.85} \mathrm{Co}_{0.05} \mathrm{Mn}_{0.10}\right] \mathrm{O}_{2}$ cathode. Energy Environ. Sci. 9, 2152-2158 (2016)

14. Kim, H., Seo, M., Park, M. H. \& Cho, J. A critical size of silicon nano-anodes for lithium rechargeable batteries. Angew. Chem. Int. Ed. 49, 2146-2149 (2010).

15. $\mathrm{Wu}, \mathrm{H}$. et al. Stable cycling of double-walled silicon nanotube battery anodes through solid-electrolyte interphase control. Nat. Nanotechnol. 7, 309-314 (2012).

16. Chen, D. Y. et al. Reversible lithium-ion storage in silver-treated nanoscale hollow porous silicon particles. Angew. Chem. Int. Ed. 51, 2409-2413 (2012).

17. Jin, Y. et al. Self-healing SEI enables full-cell cycling of a silicon-majority anode with a coulombic efficiency exceeding 99.9\%. Energy Environ. Sci. 10, 580-592 (2017).

18. $\mathrm{Hu}, \mathrm{Y}$. S. et al. Superior storage performance of a $\mathrm{Si} @ \mathrm{SiO}_{x} / \mathrm{C}$ nanocomposite as anode material for lithium-ion batteries. Angew. Chem. Int. Ed. 47, 1645-1649 (2008)

19. Liu, N. et al. A pomegranate-inspired nanoscale design for large-volumechange lithium battery anodes. Nat. Nanotechnol. 9, 187-192 (2014). 
20. Li, X. L. et al. Hollow core-shell structured porous Si-C nanocomposites for Li-ion battery anodes. J. Mater. Chem. 22, 11014-11017 (2012).

21. Liu, N. et al. A yolk-shell design for stabilized and scalable Li-ion battery alloy anodes. Nano Lett. 12, 3315-3321 (2012)

22. Magasinski, A. et al. High-performance lithium-ion anodes using a hierarchical bottom-up approach. Nat. Mater. 9, 353-358 (2010).

23. Li, Y. Z. et al. Growth of conformal graphene cages on micrometre-sized silicon particles as stable battery anodes. Nat. Energy 1, 8 (2016).

24. $\mathrm{Yu}, \mathrm{Y}$. et al. Reversible storage of lithium in silver-coated three-dimensional macroporous silicon. Adv. Mater. 22, 2247-2250 (2010).

25. Szczech, J. R. \& Jin, S. Nanostructured silicon for high capacity lithium battery anodes. Energy Environ. Sci. 4, 56-72 (2011).

26. Xiao, Q. F. et al. Inward lithium-ion breathing of hierarchically porous silicon anodes. Nat. Commun. 6, 8844 (2015).

27. Li, X. L. et al. Design of porous $\mathrm{Si}$ /C-graphite electrodes with long cycle stability and controlled swelling. Energy Environ. Sci. 10, 1427-1434 (2017).

28. Li, X. L. et al. Mesoporous silicon sponge as an anti-pulverization structure for high-performance lithium-ion battery anodes. Nat. Commun. 5, 4105 (2014).

29. An, W. et al. Scalable synthesis of ant-nest-like bulk porous silicon for highperformance lithium-ion battery anodes. Nat. Commun. 10, 1447 (2019).

30. Choi, S., Kwon, T. W., Coskun, A. \& Choi, J. W. Highly elastic binders integrating polyrotaxanes for silicon microparticle anodes in lithium ion batteries. Science 357, 4 (2017).

31. Koo, B. et al. A highly cross-linked polymeric binder for high-performance silicon negative electrodes in lithium ion batteries. Angew. Chem. Int. Ed. 51, 8762-8767 (2012).

32. Kovalenko, I. et al. A major constituent of brown algae for use in highcapacity Li-ion batteries. Science 334, 75-79 (2011).

33. $\mathrm{Xu}, \mathrm{C}$. et al. Improved performance of the silicon anode for Li-ion batteries: understanding the surface modification mechanism of fluoroethylene carbonate as an effective electrolyte additive. Chem. Mater. 27, 2591-2599 (2015).

34. He, Y., Yu, X., Wang, Y., Li, H. \& Huang, X. Alumina-coated patterned amorphous silicon as the anode for a lithium-ion battery with high Coulombic efficiency. Adv. Mater. 23, 4938-4941 (2011).

35. Forney, M. W., Ganter, M. J., Staub, J. W., Ridgley, R. D. \& Landi, B. J. Prelithiation of silicon-carbon nanotube anodes for lithium ion batteries by stabilized lithium metal powder (SLMP). Nano Lett. 13, 4158-4163 (2013).

36. Zhao, H. et al. Conductive polymer binder for high-tap-density nanosilicon material for lithium-ion battery negative electrode application. Nano Lett. 15, 7927-7932 (2015).

37. Liu, G. et al. Polymers with tailored electronic structure for high capacity lithium battery electrodes. Adv. Mater. 23, 4679-4683 (2011).

38. Liu, K. et al. Stretchable lithium metal anode with improved mechanical and electrochemical cycling stability. Joule 2, 1857-1865 (2018)

39. Liu, Y. et al. An ultrastrong double-layer nanodiamond interface for stable lithium metal anodes. Joule 2, 1595-1609 (2018)

40. Koerver, R. et al. Chemo-mechanical expansion of lithium electrode materials - on the route to mechanically optimized all-solid-state batteries. Energy Environ. Sci. 11, 2142-2158 (2018).

41. Ko, M. et al. Scalable synthesis of silicon-nanolayer-embedded graphite for high-energy lithium-ion batteries. Nat. Energy 1, 16113 (2016).

42. Coleman, J. N., Khan, U., Blau, W. J. \& Gun'ko, Y. K. Small but strong: a review of the mechanical properties of carbon nanotube-polymer composites. Carbon 44, 1624-1652 (2006).

43. Ozkan, T., Naraghi, M. \& Chasiotis, I. Mechanical properties of vapor grown carbon nanofibers. Carbon 48, 239-244 (2010).

44. Dai, H. J. Probing electrical transport in nanomaterials: Conductivity of individual carbon nanotubes. Science 272, 1861-1861 (1996).

45. Liu, R. et al. Sandwich-like CNTs/Si/C nanotubes as high performance anode materials for lithium-ion batteries. J. Mater. Chem. A 6, 14797-14804 (2018).

46. Gohier, A. et al. High-rate capability silicon decorated vertically aligned carbon nanotubes for Li-ion batteries. Adv. Mater. 24, 2592-2597 (2012).

47. Hu, L. et al. Silicon-carbon nanotube coaxial sponge as Li-ion anodes with high areal capacity. Adv. Energy Mater. 1, 523-527 (2011).

48. Green, D. L. et al. Size, volume fraction, and nucleation of Stober silica nanoparticles. J. Colloid Interface Sci. 266, 346-358 (2003).
49. Choi, S.-H. et al. Robust pitch on silicon nanolayer-embedded graphite for suppressing undesirable volume expansion. Adv. Energy Mater. 9, 1803121 (2019).

50. Ruoff, R. S., Qian, D. \& Liu, W. K. Mechanical properties of carbon nanotubes: theoretical predictions and experimental measurements. C. R. Phys. 4, 993-1008 (2003).

51. Gomez-Camer, J. L., Bunzli, C., Hantel, M. M., Poux, T. \& Novak, P. On the correlation between electrode expansion and cycling stability of graphite/Si electrodes for Li-ion batteries. Carbon 105, 42-51 (2016).

52. Obrovac, M. N., Christensen, L., Le, D. B. \& Dahnb, J. R. Alloy design for lithium-ion battery anodes. J. Electrochem. Soc. 154, A849-A855 (2007).

\section{Acknowledgements}

This work was supported by the Vehicle Technologies Program, Office of Energy Efficiency and Renewable Energy, US Department of Energy. X.C.X. and B.S.L. acknowledge the support from the Advanced Battery Materials Research (BMR) program of the US under contract number DE-EE0007787. K.M.R. acknowledges support from the DOE Office of Science, Office of Basic Energy Sciences, Chemical Sciences, Geosciences and Biosciences Division, through its Geosciences program at PNNL. The microscopic and spectroscopic characterizations were conducted in the William R. Wiley Environmental Molecular Sciences Laboratory (EMSL), a national scientific user facility located at PNNL, which is sponsored by the DOE Office of Biological and Environmental Research (BER). We thank the help provided by Dr Jianming Zheng, Dr Hui Wang, Dr HyungSeok Lim, Dr Wengao Zhao, and Mr Guomin Zhu. Help from Professor Yang-Tse Cheng and Dingying Dang on the flat punch experiment is highly appreciated.

\section{Author contributions}

H.J., X.L.L., and J.-G.Z. conceived the project. H.J. synthesized the material and performed the battery tests with help from J.H.S. and R.Y. X.Z. and K.R. experimentally measured the mechanical properties, while Y.C. and S.Y.H. carried out the simulation. L.L., Y.H., R.P., and C.M.W. helped with the material characterization and in-situ TEM study. B.S.L. and X.C.X. did the in-situ electrode swelling measurement. H.J., X.L.L., and J.-G.Z. prepared the manuscript with contributions from all other authors.

\section{Competing interests}

The authors declare no competing interests.

\section{Additional information}

Supplementary information is available for this paper at https://doi.org/10.1038/s41467020-15217-9.

Correspondence and requests for materials should be addressed to X.L. or J.-G.Z.

Peer review information Nature Communications thanks Hyun-Wook Lee and the other, anonymous, reviewer(s) for their contribution to the peer review of this work

Reprints and permission information is available at http://www.nature.com/reprints

Publisher's note Springer Nature remains neutral with regard to jurisdictional claims in published maps and institutional affiliations.

Open Access This article is licensed under a Creative Commons Attribution 4.0 International License, which permits use, sharing, adaptation, distribution and reproduction in any medium or format, as long as you give appropriate credit to the original author(s) and the source, provide a link to the Creative Commons license, and indicate if changes were made. The images or other third party material in this article are included in the article's Creative Commons license, unless indicated otherwise in a credit line to the material. If material is not included in the article's Creative Commons license and your intended use is not permitted by statutory regulation or exceeds the permitted use, you will need to obtain permission directly from the copyright holder. To view a copy of this license, visit http://creativecommons.org/ licenses/by/4.0/.

This is a U.S. government work and not under copyright protection in the U.S.; foreign copyright protection may apply 2020 